\title{
Democracy Facing Complexity the Network Form of the Public Sphere
}

\author{
Ana Maria Munteanu \\ Associate professor, PhD, Ovidius University, RO \\ Ana Rodica Staiculescu
}

Professor. PhD, Ovidius University RO

\section{Doi:10.5901/mjss.2015.v6n2s5p45}

\section{Abstract}

According to Friedland et al, "classical public sphere theory captures a particular dynamics of history, a point where reasonable discussion on politics is both possible and normative among certain groups" (2006). While the functionnalist approach was criticized by many, taking into account the powerful effects of the mass media system and impact on deliberation process, Habermas revised his theory (2006) and highlighted the centrality of the network at a number of levels, the increased complexity (multiple publics, increased fragmentation and privatisation of the opinion, the increased complexity and autonomy of political and economical systems) and "the loss of subsistemic levels, increased flows of communication from below creating instability throughout of the entire system". This instability is then related to the make sense processes, core meanings and semantic links that govern digital environments and the networks' enthelechy. In our research we used the grounded theory qualitative method (Glaser, Strauss in 1967, Strauss, 1987, Corbin,1992), to create a model that identifies the main characteristics of the object of research (Babchuk, 1996). We aimed to analyze the representation of events on the political scene in the fall of 2013 and spring of 2014 as mapped by the most important political blogs in Romania. Currently, the research field is divided in terms of methodological strategy between two approaches: those who use this type of social network analysis in political science and sociology from a perspective focused on the study and relevance of content (categories, concepts, core meanings) and a second perspective, less interested in the relationships between nodes that form a network, focusing on what Newman (2003) characterizes as "large-scale statistical properties of graphs". However, many networks can not be adequately represented by random graphs and seem to have a very different distribution from other home network links.

Keywords: network, networked public sphere, complexity, network analysis, political blogs.

\section{Introduction}

Recent developments of the Internet and mobile networks (Facebook, Twitter, Instagram, etc. ) have enabled users to create resources and share technological items, knowledge and ideas and to contribute to the setup and development of the web by incorporating the feedback in the new applications. The big impact of recent decades information technology and, especially, how the global development of blogger networks stimulate content development in the wider frame of social networks, in a society that develops rhizomatically around "space production" (Castells, 1999), are undeniable dimensions of contemporary network societies. Nowadays, content development no longer requires large budgets, and new technologies have reduced the influence of big players - media trusts owners - on access to a wide audience made up of users on different continents. . According to Habermas

Since the public sphere is increasingly becoming integrated by networks of opinion formation, its structure is a prime case for studying the importance of networks to both social theory and communication theory (Habermas, 2006).

The transversalization of the various levels of networks, an issue addressed by van Dijk (2006) ${ }^{1}$, allows for defining interactions between technology and the network society. According to him there are three main levels of networks. The first level corresponds to the practical sense of networking: individuals that create connections with family members, friends, acquaintances and colleagues. Currently, this level of growth is sustained and intensified by digital networks belonging to the Internet (e-mail) and mobile or fixed telephony. The second level is that of more structured relations within organizations. Individuals create all kinds of groups or collective agents, some of which are temporary and detached, while others are permanent and fixed (van Dijk, 2007, p. 26). All the contemporary groups have communication

1 Jan Van Dijk, 2006, p. 20. 
niches represented by telecommunications networks and computers. According to Jan Van Dijk's theory, the third level is that of societal relations. Individuals, groups, organizations form a society that is built based on discourse mediation and this applies to all subsystems of society. (Van Dijk, p. 20). But it had already been defined in the early 90s by Latour, Callon and Law in a way that gave rise to many controversies. In the actor- network theory, the authors focus on the interactions between human and non-human actors in the construction of current meanings, generating a new way of understanding the role of technology, that of actor of communication processes, not mere infrastructure or logistics of human communication. This approach is not without consequences, not just for the theory of the public sphere but also for the empirical contents that develop by embedding new media applications and multiplying knowledge. Thus, the Internet has prompted the emergence of global civil networks as an actor (Castells, 2008)), a product of the interdependencies of experts, activists and users in social movements. Habermas (2006) continues to define the public sphere issue in terms of self-regulation, media independence, and media system precisely to identify the weak links of the institutionalization of media theory, the paradigmatic framework of knowledge and deliberation. The implementation of web 2. 0 has contributed massively to decentering the public sphere (Dayan, 2009, 2013) and has reduced the influence of media trusts changing to a large extent the patterns of public and political culture and communication by shifting the focus from the (public) show to the discussion forum (which is sensitive to micro-perception changes and values micropolitics and even the aesthetics of the Internet as participatory modes, action tanks) as well as to the incorporation of sociological knowledge into cutting-edge applications provided by the Internet. Studies on the decentering phenomenon reflect different epistemological positions and continue to involve difficult deliberations. The model that Daniel Dayan (2013) refers to is "the implicit model of a conversation between a given nation- state and the corresponding civil society, with central media connecting centers and peripheries". He claims that: After having been structured for a long time in national terms and dominated by central television organizations, public spheres have grown in a number of directions, most of which involve a post-national dimension. According to Dayan this geography of centers and peripheries has been submitted to many waves of destabilization among which three directions being particularly significant: 1 . The model of national television relativized from above by mega television networks offered to world audiences that are, in fact, nationally or regionally flexible (Al Jazeera, BBC World, TV5 Monde, CNN International, etc. ); 2. the national model relativized from below by new media and digital public spheres that subvert national space through decentered interactions described in terms of rhizomes, networks or capillarity; 3. the national model challenged by the multiplicity of centers catering to the same peripheries. It is challenged sideways (Dayan 2013) by "transnational" televisions that broadcast their programs across national borders that cater to immigrant populations and help in constructing or reconstructing spectral communities, disappeared/lost nations, forgotten empires, actual diasporas. Although Jürgen Habermas still continuing describes the manner in which the public sphere may rely on public institutions as sluices of public rationality under increased instability of the directivity of public sphere communication flows and implicitly impacts on institutional and public systems. In their analysis of Habermas's supplement of the theory of the public sphere in "Between Facts and Norms" and "Political Communication in Media Society: Does Democracy Still Enjoy an Epistemic Dimension?" Friedland et al, highlighted his stance on "the centrality of the network at a number of levels" and "the loose/loss of subsistemic levels, increased flows of communication from below creating instability throughout the entire system".

\section{Blogosphere as Rhizomatic Public Sphere}

Political blogosphere can be approached as public network sphere, a dynamic subsystem generated by the interdependencies among innovation, connectivity features and uses (practices) as modes of interaction among distant individuals in terms of microperception, micropolitics and "singularities in action" (Massumi, 2010). The emergence of semantic blog networks and forum activity strengthens both content creators' autonomy from political, cultural elites and professional journalists. In this research we focused on:

- If and how the Romanian political blogosphere meets the requirements of a public sphere.

- If, how and by what elements blogs - as space resulting from intensifying interactions - are an extension I development of social and political identities in the online environment.

- How do motivations, choices and personal preferences relate to communication standards, how are they internalized, framed or modified by blogging?

Blogs, the related practice - blogging and the blogosphere, as space generated by interaction closely related to the other social networks, discussion forums, Facebook, Twitter and Linkedin, etc. , reflect a shift of emphasis from the interconnected individual and self-generating log, as embodiments of the singularity of action (Massumi, Prost, Boucher, 2010), to aggregations focusing on content, "modes of speech" and nuclei of discussion which represent "action tanks" 
grouped into semantic networks. . On the one hand, blogs generate and develop as informal networks of opinion and the development of blogosphere is the result of integrating blogs into semantic networks, characteristics of the "interconnected public sphere", including connection modes common levels, interest groups, digital media hosting both discussion forums and online advertising, etc. being identifiable by the companies' strategies of recruiting influential bloggers to make positive comments on their services and products, tutorials posted by companies to facilitate the use of their products and services, etc. One such example is the political blogosphere, as well as the institutional blog integrated into public relations, which resizes the communication strategies of certain organizations, institutions, systems, local national and transnational actors, the stake being the optimization of the public communication interface by use of platforms and online formats, this type of blog being linked to the evolution of public relations towards "cohesion and performance through communication" (Iacob, Cismaru, Pricopie, 2011) and, especially, the adoption of tactics to conceal asymmetries among actors in the digital environment, implicitly the adaptation of strategies taking into account the characteristics of this type of space. Globally, tensions among individuals interconnected in decentralized networks, as well as the integration in the range of influence of territorialised systems as a set of institutions, public commitments and government strategies, provides an insight into the manner in which globalization processes shape social networks, public discourse and identification, but political and public affiliation and identity, in turn, are influenced by the language environment which reflects mentalities, social constraints as well as the continuous tension between the personal and the public sphere, i. e. we can relate to the Diaspora, but not in terms of the "resurrection of spectral communities and nations related media devices (the third type of destabilized public sphere mentioned by Dayan, but, in our opinion, as living forms of transnational political and public life related to flexible citizenship and transnational labor, business, study, marriage, tourism mobility, pilgrimages etc. Identities and their dimensions, such as role, class, gender, nationality, ethnic relations constantly establish connections as well as distinctions between individuals and society and influence behavior patterns, mentalities, thoughts, attitudes and feelings animated by network energy and the status of participant to debates as "modes of speech and action tanks". Social identity theorists argue that the society is a complex system of influences generated by interactions among individuals and that these are products, which, in turn, influence the social structures that they create (Burke, Stets, 2009,p. 3- 4). The social relations network shapes real and virtual life as well as social imagined existence. People as social beings can belong to different social structures and cultural spaces being interconnected in a wide network of relatives and non-relatives, in very different ways, through different types of interdependencies. By this wide variety of social contacts people build their social life and constantly redefine their identities and interactions (Dijk, 2006,p. 156). The psychological dimension (exposure/dissimulation of the self through authentic as well as fictional identities) must be related to the emergence of modes of speech and participation in the network that change the empirical contents of constructivist anthropology, both the capturing of transformations through the gentrification binomial vs. the "common horizon" and the centrality of the network form being necessary to capture precisely the mobility, energy, "cross-" features and "autonomy from space" of interactions. In " Nomadology-The War Machine" (1986), Deleuze and Guattari talk about the social space generated, to a greater extent, by multiplying interactions than by pre-existing, fixed conventions and arrangements, and propose an ethics of creativity and resistance, an ethics of imperceptible becoming through strategies of continuous invention of "arms", movement. Against this background, the philosopher Brian Massumi (who translated the works of the two authors into English) has developed an approach of the Internet that he defines as aesthetics, microperception and micropolitics, in which each member, as a singularity of action provides a creative answer to the need to come together (Massumi, 2010), the success being ensured by reciprocity and trust. The development of recent decades information and communication technologies has led to changes both at the personal and the social life level as a result of their increasingly wider scale use, attracting members of different social and professional groups without a clear geographical boundaries (Giddens, 1984) leading to the emergence of a new model and new forms of social interaction, not only at the general public level but also in the government and corporate area.

\section{Network Energy as Multiplying Effect}

The design and technological innovation incorporated into networks and their uses have contributed to the intensification of the exchange of information and multiplication of social networks. This phenomenon defined as entelechy (Latour, 2005), is more than a movement of social capital across physical and intellectual borders, and more than an information and knowledge economy, being a micropolitics fueled by the energy of flows that releases the power of communicative reflexivity at the inter-subjective level (sharing of values, creating solidarity, participation in the deliberative (de)legitimization of policy, awareness of local and global challenges, etc. ) as well as a capacity to influence political and economic decision which may counter-balance, to some extent, the action of macro level steering factors. Social 
networks energy is fueled by reciprocity and participation as a ways of transformation and feedback in the process of continuous adaptation to the successive changes of the new economic environment as against the gentrification of offline contexts. In view of these issues, our research starts from the assumption that the revolutionizing of the current social life dynamics is the effect of the virtual space interaction of large groups made up of people meeting by chance through blogs generated by online platforms (Lowrey, u. a. , 2011. Blogs as "signs of participation" and "action tanks" affect public opinion networks by intensifying exchange of information and social meaning assignment/ construction processes, but the interaction between blog creators and users can produce effects not only at the level of life and professional experience, but also by pressure and change at the political and public level, including in government sciences.

\section{Methodological Framework}

Grounded theory is an inductive method which seeks to generate a theory starting from a data corpus, based on plausible relationships among concepts and sets of concepts. This method was chosen because it is a qualitative manner of developing a theory through a "systematic process that highlights the significance of concepts and their correlation at content level", and therefore it addresses the formation of a network around a space development (blogosphere) which is also a development of meaning depending on micro-perception and the distribution of knowledge (information, concepts, meanings assigned to events in the processes of interaction) in which both human (bloggers) and non -human actors (traffic data analysis software, search engines, databases, bloglinks, blogosphere) participate, technologies being considered by Sebeok - in "An Introduction to Semiotics" extensions of the living-result of intelligence and, as such, included by him in the creation of signs (Sebeok 2008). The generation and development of concepts, categories and suggestions is a process that can underlie a future quantitative study. The starting point of the investigation in this research methodology is the study of a corpus of texts and the identification of variables, called categories, concepts, properties. Furthermore, it is an inductive method, starting from the study of the phenomenon it represents, in our case the dissemination of information on political events and their reception by Romanian bloggers. Researchers who use this methodology are interested in the modes of action and interaction of different types of categories, concepts, properties. The ability to label these variables and the relationships among them is termed 'theoretical sensitivity'. This has important consequences for the political effects of the blogosphere. We thus start from the following assumptions about the political blogosphere as "network public sphere":

- If different distributions of the links between nodes are associated with different forms and levels of participation and political efficacy. In particular, as we have tried to argue,

- If, to the extent that the links distribution is preferential (reflecting an intention to influence) there appear important consequences for the manner in which blogosphere affects politics (Davies, 2013)

More precisely, many networks seem to have asymmetric distributions where most nodes have a relatively small number of links, but a small number of nodes have a disproportionately large number of links. In such networks, the best linked nodes will have a much larger number of links than the less well connected nodes. The distribution of influence power is particularly likely to be found in growing networks in which:

- If nodes that already have a large number of links are more likely to receive links to new nodes than nodes that have few such links.

In such networks, the initial advantages are the dissemination of information through nodes rich in links and are likely to become richer in time, generating a distribution of the power to influence relations by participants. This hypothesis was tested by other researchers as well. If web pages are more likely to link to other websites that already have a relatively large number of links (Barabási 2000; Adamic and Huberman 1999, Hindman et al. 2003) therefore based on the number of links. The nodes were also analyzed from a techno-operational perspective by Gene Amdahl as early as the $60 \mathrm{~s}$, assigning nodes a role in the aggregation of networks that had not previously had contact, the aggregation allowing for the "parallel processing" of information and generation of new nodes ( Amdahl, AFIPS Computer Conference, 1967). By the large number of preferential links (blogroll and links in messages) nodes (authors, but also web pages with a large number of links) networks develop a capacity for parallel processing of information around the nuclei of meaning. But the reaction too plays a significant role in the redistribution of the power to influence that bloggers have to shape a/an (op)position in the public network sphere and in real political life (see also the Tea Party movement in the US). Compared to offline networks, bloggers have the advantage of a first mover in formulating opinions (an advantage previously belonging exclusively to the media). Another comparative advantage of blogs in political discourse is their low cost of real-time publishing. Immediately after an event of great interest, be it for a presidential political debate, a terrorist attack or a major policy initiative, bloggers can post their reactions right away. (Kahn, Kellner, 2005). This analysis, which identifies labels, categorizes and describes the phenomena and properties mentioned in the text, 
includes: a) open coding, following which code files that can then be used in reports are created; b) axial coding, identifying causal links between different codes, categories, properties; c) selective coding, which sets a category as the central group, and all other categories relate to this basic category. (Strauss, Corbin, 1990). By generating codes, we grouped the concepts in the corpus consisting of entries from 30 blogs around the online community response to political events, especially to political campaign. Using open coding, we aimed to describe the blogosphere on the three major areas: the European Parliament elections, the ruling coalition, the president elections- by setting attributes and actions that are taken from posts concerning these events. In this process initial data were collected from each category of documents, they were analyzed, the codes were then selected according to their relevance in the main document. Thus we moved from the source text to a qualitative analysis. This process helped in determining the relevant categories, namely those with the highest number of occurrences in the analyzed unit. A computer assisted research program was used, more precisely Atlas. ti, several stages of data processing being followed. According to Keren (2006): 1) original texts relevant to the virtual community regarding the existence of an online representation of political events were processed. After selecting the documents, 2) specific coding procedures were used in data analysis. The following categories were identified through the process of open coding. 3) indicators of political events perception in the virtual environment were established based on the text. 4) linking the relevant categories that appear frequently in the text have formulated conclusions.

\section{Interest for Political Information}

In choosing the corpus we selected Romanian political blogs, according to how they define their interests and how websites and search engines (browsers) select them as relevant for accessing information on political events in Romania. Additionally, we used blogroll, a nexus of links and references (preferential and cross references) that the blogs chosen make to each other, thus making up an online information dissemination node. Despite some limitations, there is agreement on the direction of evolution of blogs, the fact that they play an increasingly important role as a forum for public debate, which has consequences for media, political life and governing. Given the differences in resources and organization compared to other public sphere actors, the question arises

When and how can bloggers exert an influence on political results and political life?

Perhaps the most important difference between blogs and media is determined by the fact that blogs are network phenomena based on hyperlinks, links between blogs. The links between blogs take two forms. First, many bloggers have a permanent "blogroll" on their website; a list of blogs they read frequently and, especially, they admire, having common interests, with links to the general URLs of those blogs (e. g. , with links to the homepage of the blog ). Secondly, bloggers can write special messages containing links to other blogs. Unlike the blogroll links, links in messages will move from the first page and will be archived as new messages replace old ones in time. Usually, such messages link directly to a specific post (posted content), on another blog (rather than the general URL of the blog), and may also provide some comments on the posted content. The public nature of the blogosphere is generated, on the one hand, by links and page views that are the trading currency of the blogosphere and, on the other hand, Blood (2002, p. 98) suggests that "the most reliable way to get traffic [in readers] is by a link from another blog. " This follows from the nature of hypertext and users' choices. When a blog adds a link to another blog, the former blog readers of are more likely to read an article by simply clicking a hyperlink than if it's absent. If they like what they have read, they can even become loyal readers of the second blog. (Highfield $u$. a. , 2011). Thus, bloggers are very interested in discovering other blogs which link to their own blogs and can discover such blogs through a variety of means. These include: (1) traffic data analysis, (2) general search engines, e. g. Google (http: //www. google. com), (3) databases searched by bloglinks, such as Technorati (http: //www. technorati. com), (4) the Ecosystem blogosphere (http: //www. truthlaidbear/ ecosystem. php). We can note the active / participatory behavior of bloggers in the use of new media, both as authors and as mediators - linking agents, and communicative influence by cognitively affecting the network - conceptual sensitivity.

\section{Identification of Nuclei of Discussion}

We have analyzed the blogosphere in Romanian to discover networks of discussion around areas of Romanian politics and public issues. Starting with an initial set of over 25,000 blogs, using the empirically grounded theory method in the content analysis of social networks to identify a very active "nucleus of discussion" of 100 blogs. They were grouped according to their activity, the number of citations and posts, and the resulting segmentation is characterized both by automated analysis and by a strong human content. The main findings on the combination of these two features point to the concept of "system of preferential attachments" (Sola-Price, 1976), as follows: 
- Unlike fellow bloggers in the US and other countries, Romanian bloggers prefer platforms that combine typical blog features with some features of social networking services (SNS) such as Facebook. Romanian Blogging is dominated by a handful of SNS hybrids. "

- While most of the Romanian blogosphere is very fragmented depending on the platform they use and the topic that they focus on that they entered when registering the login in search engines, there is a central issue including most political affairs and public discourse. This nucleus consists mainly, but not exclusively, of blogs on the Wordpress platform.

The central issues may be grouped into four main topics:

1. Politics and public affairs (including news focusing on discussions, business and finance, social activists and political movements)

2. Culture (including literature, cinema, mass culture and pop culture)

3. Regional area (bloggers in Belarus, Ukraine, Armenia, Israel, etc)

4. Uses and gratifications (paid blogging and blogging which, in exchange for its activity, gets small benefits such as free samples, invitations to participate in different events)

Bloggers from the political and economic area cover a wide range of ideologies and political agendas, which may include the fact that many people participate in discussions on political issues with an approach different from the political platform of a party, whether independent or affiliated to political parties other than the page that hosts the discussion. A different category is that of bloggers who identify with the opposition and form in the virtual space a "democratic opposition" through the large number of marks of identification with a national interest. Pro-government bloggers are not particularly important and do not form a separate group, but are mostly located in a network region (neighborhood) providing a general discussion of the Romanian political agenda. There is a concentration of bloggers affiliated with nongovernmental organizations in supporting a particular policy initiative of the government, this category including particularly the environmental movement or those who support reforms in education. We have found evidence of political and social mobilization, particularly in those groups affiliated with political and social movements in the opposition at the time of the online mobilization. The first step of analysis of the "nuclei of discussion" in the Romanian political blogosphere highlighted two features of political behavior in the digital environment. It is much more independent, internationalized and opposition-oriented than most Internet users in Romania and far more than most users of traditional media means, based on private television channels, which are often associated with a certain political ideology. Popular political clips on YouTube focus on corruption scandals and abuse of power by political elites, government and local politicians. After determining the main areas of the online reception of political events, in the next step we used the corpus collected from the main online political blogs and, from these, the posts with over 1,000 views, adding, as a criterion, their presence on http: //roblogfest. ro/ and selection using http: //www. zelist. ro/monitor/. ${ }^{2}$

\section{Development of Axial Categories (The Funnel Model)}

Kathy Charmaz compares the grounded theory model with a funnel: in spite of the different forms of the main documents, the modeling process based on coding prevents data loss, and selecting categories according to their relevance in the text acts as a funnel that allows for the fractionation in small sections, turning the primary text into codes and small units that are easier to manage. (Silverman, 2013). In the funnel process of conceptualizing we identified the nodes in the space of political discussion by "settlements" and "neighborhoods" as "preferential attachment systems" (Price, 1976). The random interactions hypothesis underlying objective science - as social physics based the critical mass of data - has no explanatory relevance for political blogosphere which develops around "nuclei of discussion" i. e. a complex system of influences. Thus, codes developed in the first step were filtered by the development of axial categories, according to their relevance in the primary document (e. g. the frequency of the executive conflict, manipulation, political agenda phrases). Comparing the indicators proposed for measuring and presenting the daily political events in Romanian blogosphere, we

\footnotetext{
2 The list of influential political blogs ( large number of posts) http://patrasconiu.blog.cotidianul.ro/, http://codexpolitic.us/, http://voxpublica.realitatea.net/fumurescu, http://corinacretu.wordpress.com/ http://www.coins.ro/politic, http://moshemordechai.wordpress.com/ http://sutu.ro/ http://stareanatiunii.com/, bloguluotrava.ro ? http://1blogpolitic.blogspot.ro/? timesnewroman.ro ? theodora0303.wordpress.com ? stelian-tanase.ro ? gandeste.org ? http://horiapana.wordpress.com/? http:///bloggeriliberali.blogspot.fr/ http://civitaspolitics.org/ http://politicata.wordpress.com/ http://blogevent.ro/ http://politicstand.com/ http://theophylepoliteia.wordpress.com/ http://karikaturapolitika.wordpress.com/ http://tismaneanu.wordpress.com/ http://www.rodicaculcer.ro/ http://www.openpolitics.ro/ http://www.smartpolitics.ro/ http://www.alinagorghiu.ro/ http://www.ionutiancu.ro/ http://blogponta.wordpress.com/, http://vasiledancu.blogspot.fr/, http://sociollogica.blogspot.fr/?wref=bif http://riddickro.blogspot.ro/ http://national-liberal.ro/http://www.contributors.ch/ http://politicstand.com/ http://www.zoso.ro/
} 
can say that "mistrust in the political class" is a standard of speech in the digital space in that bloggers, regardless of their political affiliation (liberals, right-wing socialists (. . ), believe that political events giving rise to debates are often ways to manipulate public opinion and means of achieving a political agenda that do not generally reflect the general interest, but a short-term interest, that of winning the elections. These entries in the digital space of Romanian political environment could be assigned to the network public sphere impacting on the shaping of public opinion in that they have thousands of views and are considered a benchmark for undistorted information. Code selection (Keywords) was done according to the high frequency of occurrence in the text. Membership relations of codes arise from comparing the relevant categories, validating their membership in the category of political event indicators. ${ }^{3}$ Metacodes - for example, highlighting conflicts, mistrust in politicians, the relationships with blogs determining political activism, the share of the same posts by other bloggers with similar opinions - were subsequently used to classify the entry corpus by their addition. In the next section, we could see later that these codes are grouped by the frequency of citation in the original text around the concept of "mistrust in political actors", which the indication of the means of political manipulation plays a central role. Data analysis shows that the presentation of political events is associated with sharing of everyday events in terms of a deficient political agenda, and indicates disappointment and mistrust in the Romanian political class. Political involvement, interest in politics and a future electoral event, constantly affect the visibility and influence of blogs. Both electoral interest and political involvement are significant and positive indicators for the interest in political blogs. However, objective presentation of information, in the style of formal media, is not as popular as presentation of personal opinions on the political event presented. Political involvement of the virtual environment has increased greatly since blogs are classified as credible sources of information. Instead, Internet users interested in politics seek and rapidly form a selection of logs with similar interests and views. Blogs allow for the presentation of recent events, often bring viewpoints of specific interest to their users. The codes cited for the area "strategies of majority insurance" can develop into sub-categories such as "violations of constitutional provisions, international influence, regional interests, public interest, political games". Here, other codes such as "political ability, but also political abuse", "political discourse" play an important role in establishing the importance of this criterion. The central topic is the "part - whole" relationship through the "political agenda" and "political speech" categories, the relations between the codes revealing the logics resulting from the integration of categories addressing the political crisis rhetorically highlighted by electoral campaign speeches. Previous research indicated that, while readers expect traditional media to maintain the honesty and balance standards (Metzger et al, 2013), these expectations do not extend to the blogosphere (Bruns, 2006; Lasica, 2002). In fact, blog supporters see any deviation from neutrality as an advantage that allows for a more detailed and in-depth examination of problems. It may also suggest that blog readers are attracted to sites that share their views and therefore have a potential polarization effect. We assigned metacodes to groups of topics (for example, reasons which prompted the description of a particular subject, their presentation in the social context, their relation to the target audience of the blog, similarities I differences between the presentation of an event on different political blogs, the sense of solidarity, asserting individualism, asserting mistrust in state policy), which has facilitated the analysis of posts.

The sharing of political events by blogs proved to be politically relevant being strongly influenced by a body of elements that define user behavior: a) trust in blogs, b)political involvement, c)political knowledge,d) readers' political interest. The research has identified the mediating role of the blog author (owner). According to Latour, the role of mediator in the digital network is distinct from that of intermediary.

\footnotetext{
${ }^{3}$ political ability, abuse, international actors, political agenda, elections, America, electoral campaign, independent candidates, ruling coalition, executive conflict, corruption, determining culpability, democracy, political abuse, disappointment, political discourse, ignorance, violations of constitutional provisions, international influence, regional interests, public interest, political games, lack of mobilization, political dispute, majority, manipulation, media manipulation, manipulation of state institutions, mistrust, dishonesty, political opportunism, opposition, voter passivity, President-Government, economic problems, radicalization, corrupt system, resentments, responsibility, risks, Russia, weak political power, polls, rule of law, strategies of majority insurance, EU, voters. 


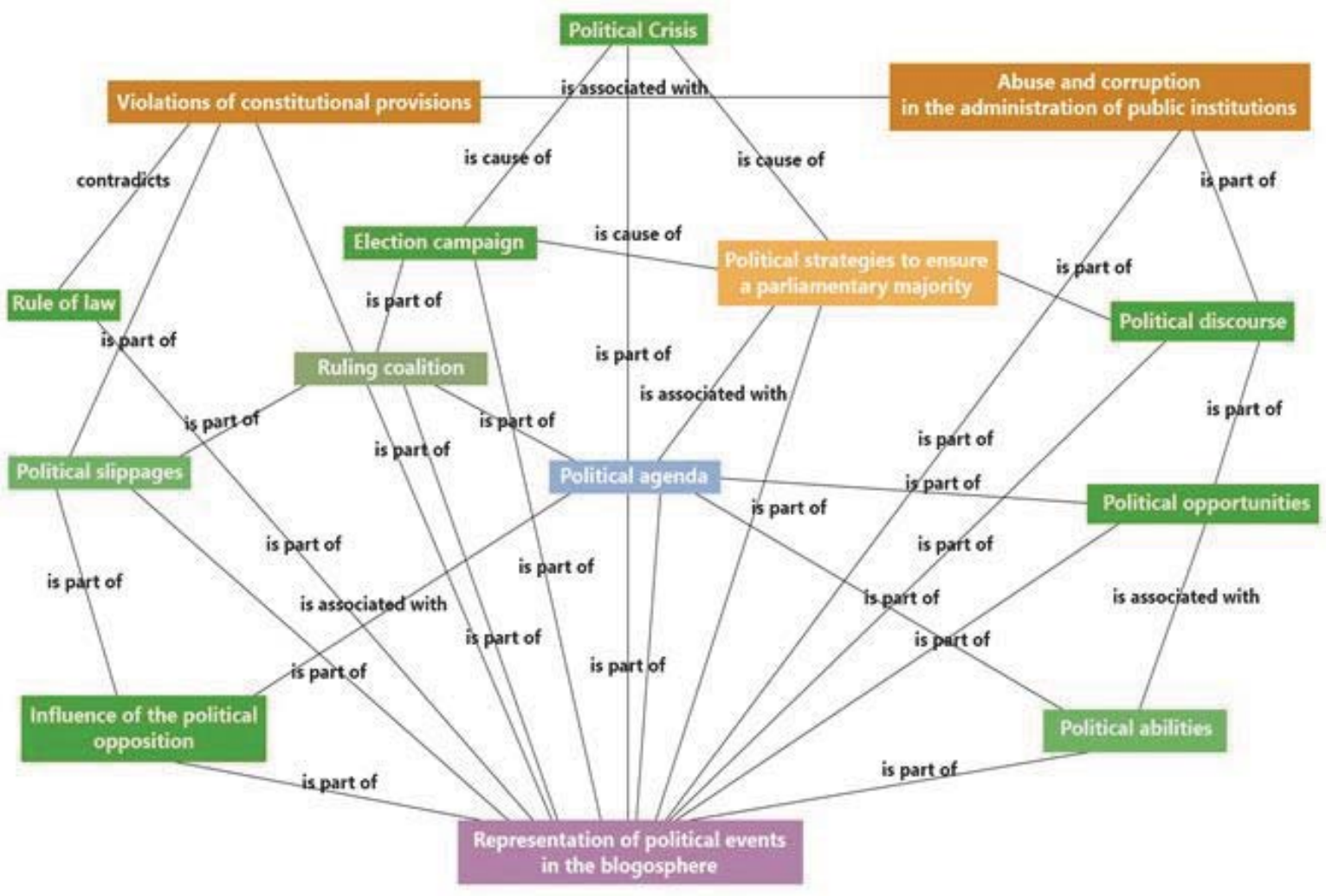

Figure 1. Representation of political phenomena in blogosphere 4

If the intermediary merely shares and disseminates information, and, therefore, generates forces that he/she is not interested in, the mediator is an entity that produces and determines differences. The blog owner falls into the second category. Thus, political events are shared preferentially by bloggers, particularly according to their affiliation and political involvement, but once shared they can influence their readers' opinions and decisions. Media studies suggest that the public can judge news based on its knowledge as biased and therefore will judge its content as less credible (Arpan \& Raney, 2003; Gunther \& Liebhart, 2006; Gunther \& Schmitt, 2004 ).

\section{Conclusions}

The Romanian network is largely made up of blogs that are not based on selling advertising space. These hybrid platforms or social networking systems ("SNS") combine typical features of open blog platforms (e. g. , Blogspot, Wordpress), with some features of closed social networking services (e. g. Facebook, MySpace). Romanian-language blogosphere is dominated by four such SNS hybrids (blog. ro, wordpress, blog. mail. ro and LiveJournal). The online information consumption of Romanian bloggers is more independent, mainly internationally and animated by an oppositional spirit than most Internet users in Romania and far more than most users of traditional media means, based on private television channels, which are often associated with a certain political ideology. Political involvement, interest in politics and a future electoral event constantly affect the visibility and influence of blogs. Political involvement of the virtual environment has increased greatly since blogs are classified as credible sources of information. Electoral interest and political involvement are significant and positive indicators for the interest in political blogs. Internet users interested in politics seek and rapidly form a selection of logs with similar interests and views. While readers expect traditional media to maintain the honesty and balance standards (Metzger et al. , 2003), these expectations do not extend to the blogosphere (Bruns, 2006; Lasica, 2002). In fact, blog supporters see any deviation from neutrality as an advantage that

${ }^{4}$ cf. ATLAS.ti Alternatives and Similar Software - AlternativeTo.net (alternativeto.net/software/atlasti/); http://www.zelist.ro/monitor/ 
allows for a more detailed and in-depth examination of problems. It may also suggest that blog readers are attracted to sites that share their views and therefore have a potential bias effect. The analysis results confirm the hypothesis that Romanian political blogosphere - a macro phenomenon resulting from the dynamics of online connecting behaviors develops as a public social network sphere maintaining elements of continuity between the real and the virtual as well as between the communication modes and genres which it nevertheless continually transforms.

\section{References}

Adamic, Lada, A. , Huberman, Bernardo, A. (1999): Technical comment to 'Emergence of Scaling in Random Networks', Vol. 28615 October 1999, pp. 509-512.

Arpan \& Raney (2003): Arpan, L. , \& Raney, A. A. (2003). An experimental investigation of news source and the hostile media effect. Journalism and Mass Communication Quarterly, 80 (2), 265-281.

Babchuk, Wayne A. (1996): „Glaser or Strauss? Grounded theory and adult education“. In: Proceedings of the 15th Annual Midwest Research-to-Practice Conference in Adult, Continuing, and Community Education. ERIC, p. 1-6.

Réka Albert, Hawoong Jeong \& Albert-László Barabási (2000): Error and attack tolerance of complex networks. In: Nature 406, 378-382 (27 July 2000)

Benkler, Yochai (2006), The wealth of networks: How social production transforms markets and freedom. Yale University Press.

Bruns, Axel (2008): Blogs, Wikipedia, Second Life, and Beyond: From Production to Produsage. Peter Lang.

Bruns, Axel; Burgess, Jean, Highfield, Tim (2011): „Mapping the Australian Networked Public Sphere“. In: Social Science Computer Review. 29 (3), p. 277-287.

Burke, Peter J; Stets, Jan E (2009): Identity Theory. Oxford; New York: Oxford University Press.

Corbin, Juliet M. ; Strauss, Anselm (1990): Grounded theory research: Procedures, canons, and evaluative criteria. Qualitative sociology. $13(1)$, p. 3-21.

Castells, Manuel, (1999): Information Technology, Globalization and Social Development; UNRISD Discussion Paper No. 114, September 1999

Castells, Manuel (2008): The New Public Sphere, The New Public Sphere: Global Civil Society, Communication Networks, and Global Governance, The Annals of the American Academy of Political and Social Science, vol. 616, no. 1, p. 78-93.

Davies, Andrew (2013): Blogs as 'minimal' politics. In: Dialogues in Human Geography. 3 (1). p 81-84.

Dayan, Daniel (20090. Sharing \& Showing : Television, Attention, Monstration " Annals of the American Academy of Social and Political Sciences. Vol 62,No1,p. 19-31.

Dayan, Daniel (2013): In Depth-Analysis Overhearing in the Public Sphere, http: //www. deliberatelyconsidered. com/2013/02/overhearing-in-the-public-sphere/

Deleuze, Gilles; Guattari, Felix (1986): Nomadology-The War Machine, Wormwood Distribution, Seattle.

Giddens, Anthony (1984): The constitution of Society, Cambridge, Polity Press, 1984.

Gunther \& Schmitt, (2004): Mapping Boundaries of the Hostile Media Effect. In: Journal of Communication, V Volume 54, Issue 1, p. 5570 , March 2004

Gunther \& Liebhart, (2006): Gunther, A. C. and Liebhart, J. L. (2006), Broad Reach or Biased Source? Decomposing the Hostile Media Effect. Journal of Communication, 56, p. 449-466.

Habermas, Jurgen, (2006): Political Communication in Media Society: Does Democracy Still Enjoy an Epistemic Dimension?The Impact of noormtive Theory on Empirical Research, Communication Theory, 16 (2006) 411-426.

Habermas, Jürgen (1992): Between Facts and Norms, Between Facts and Norms: Contributions to a Discourse Theory of Law and Democracy, MIT Press.

Hindman Matthew, Tsioutsiouliklis, Kostas, Johnson, Judy „A. , (2003) "Googlearchy": How a Few Heavily-Linked Sites Dominate Politics on the Web. http: //www. cs. princeton. edu/ kt/mpsa03. pdf

Lewis A. Friedland, Hove, Thomas, Rojas Hernando, The networked Public Sphere, In Javnost-The Public, Volume 4, p. 5-26.

Lowrey, Wilson; Parrott, Scott; Meade, Tom (2011): „When blogs become organizations“. In: Journalism. 12 (3), p. $243-259$.

lacob, Dumitru; Cismaru,Diana-Maria; Pricopie,Remus (2011), Relațiile publice. Coeziune și eficiență prin comunicare, Edit. Comunicare, 2011.

Kahn, Richard; Kellner, Douglas (2005): „Oppositional politics and the Internet: A critical/reconstructive approach“. In: Cultural Politics. 1 (1), p. 75-100.

Keren, Michael (2006): Blogosphere: The new political arena. Lexington Books.

Latour, Bruno (2005), Reassembling the Social An Introduction to Actor-Network-Theory, Oxford University Press, Oxford.

Lasica, J. D. (2003) Blogs and journalism need each other, Retrived on the 7th of January 2006 from http://jdlasica.com/articles/ nieman. html

Leskovec, Jure, Adamic, Lada A. , Huberman, Bernardo A. (2007): „The dynamics of viral marketing“. In: ACM Transactions on the Web, Vol. 1, No. 1, Article 5, http: //www-cs. stanford. edu/people/jure/pubs/viral-tweb. pdf

Massumi, Brian; Entretien avec Brian Massumi, edited by the Publication Committee Boucher, Marie-Pier; Prost, Jean-François (2010), Adaptive Actions, AA, 2010.

Metzger, Myriam,J. , Flanagin Andrew,J. , (2013): Credibility and trust of information in online environments: The use of cognitive 
heuristics, Volume 59, Part B,December 2013, p. 210-220.

Sebeok, Thomas, (2001): An Introduction to semiotics. University of Toronto Press.

Silverman, David (2013): Doing qualitative research: A practical handbook.

Strauss, A. ; Corbin, Juliet (1990): „Open coding“. In: Basics of qualitative research: Grounded theory procedures and techniques. 2, p. $101-121$.

VanDjik, Jan (2006): The Network Society, Social Aspects of New Media, Sage Publication, London, 2006

http: //roblogfest. ro/

http: //www. technorati. com

http: //www. truthlaidbear/ecosystem. php

http: //www. zelist. ro/monitor/ 